\title{
COMPARTIMENTAÇÃO GEOMORFOMÉTRICA DA BACIA HIDROGRÁFICA DO ARROIO CAVERÁ - RS
}

\author{
GEOMORPHOMETRIC COMPARTMENTATION OF \\ HYDROGRAPHIC BASIN OF THE ARROIO CAVERA - \\ RS/BRASIL
}

Paula Mirela Almeida Guadagnin

Instituto Federal de Santa Catarina paulaguadagnin@yahoo.com.br

RomarioTrentin

Universidade Federal de Santa Maria romario.trentin@gmail.com

\begin{abstract}
RESUMO
O estudo das formas do relevo, nos últimos anos, tem adquirido novas dimensões, análisesdescritivas dão lugar a estudos integrados que consideram a complexidade da superfície terrestre.Com o advento dos Sistemas de Informação Geográfica - SIGs e o desenvolvimento de métodos de geoprocessamento é possível representar a superfície terrestre na forma de modelos numéricos ou Modelos Digitais do Terreno (MDT), os quais possibilitam a análise topográfica de uma área de interesse, assim como o cálculo automatizado de uma série de variáveis relacionadas.A parametrização do relevo referese à representação quantitativa das características morfológicas da paisagem descritas de forma contínua por meio de equações aplicadas a modelos numéricos de representação altimétrica, os MDTs, que derivam os atributos. O presente estudo foi realizado na bacia hidrográfica do Arroio Caverá, localizada na região oeste do Rio Grande do Sul, por meio de técnicas de geoprocessamento associadas à análise digital do relevo onde determinou-se a representação paramétrica das formas do relevo, com emprego de atributos topográficos obtidos de um MDT, elaborando-se uma compartimentação geomorfométrica. Para tal classificação utilizou-se uma proposta de mapeamento geomorfométrico automatizado apresentado por Silveira \& Silveira (2013), a partir dos preceitos de Iwahashi e Pike (2007) que é realizada através do cruzamento de informações e atributos topográficos gerados por meio de um SIG e hierarquizados através de uma árvore de decisão baseada em valores pré-definidos, com base em conhecimento da área. Foram empregados quatro atributos topográficos: altimetria, declividade, perfil de curvatura e plano de curvatura que resultaram na definição de doze unidades de relevo.
\end{abstract}

Palavras-chave: geomorfometria;atributos topográficos; unidades de relevo; bacia hidrográfica. 


\begin{abstract}
The study of landforms, in recent years, it has acquired new dimensions, descriptive analyzes give rise to integrated studies that consider the complexity of earth's surface. With the advent of Geographic Information Systems - GIS and development of methods of geoprocessing is possible to represent the surface earth in the form of numerical models or Digital Terrain Models (DTM), which allow the topographic analysis of an area of interest, as well as the automated calculation a series of related variables. The parameterization of the reliefrefers to the quantitative representation of morphological features of the landscape continuously described by equations applied to numerical modelsaltimetric representation, the MDTs, which derive attributes. This study wascarried out in the watershed of ArroioCaverá located in the western region of Rio Grande do Sul, through the geoprocessing techniques associated with digital analysis relief which determined the parametric representation of the relief forms, with use of topographic parameters obtained from an DTM, is elaborating onegeomorphometric partitioning. To do this classification we used a proposal for automated mapping geomorfométrico presented by Silveira\&Silveira (2013), from the precepts Iwahashi and Pike (2007) that is performed by crossing topographical information and attributes generated by the GIS and hierarchized through a decision tree based on values predefined, withbased on knowledge of the area. Four topographic attributes were employed:altimetry, slope, profile of curvature and plan of curvature that resulted indefinition of twelve units of relief.
\end{abstract}

Keywords: geomorphometry; topographic atributes; relief units; watershed.

\title{
INTRODUÇÃO
}

O estudo das formas do relevo, nos últimos anos, tem adquirido novas dimensões. Segundo Silveira e Silveira (2013), as análises puramente descritivas de outrora dão lugar a estudos integrados que consideram a complexidade da superfície terrestre, pois as discussões e demandas que emergem do conhecimento geomorfológico atualmente são mais específicas, visando aplicabilidade e melhor compreensão dos processos e fenômenos correlacionados.

Com o advento dos Sistemas de Informação Geográfica -SIGs e o desenvolvimento de métodos de geoprocessamento, é possível representar a superfície terrestre na forma de modelos numéricos ou Modelos Digitais do Terreno (MDT), os quais possibilitam a análise topográfica de uma área de interesse, assim como o cálculo automatizado de uma série de variáveis relacionadas (VIDALTORRADO et al., 2005). Segundo Hengl (2003 apud Silveira et al., 2013), parametrizar a morfologia do relevo através de um SIG é o procedimento de extrair os atributos quantitativos da topografia 
de um MDE. Para Wood (1996) a parametrização do relevo refere-se à representação quantitativa das características morfológicas da paisagem descritas de forma contínua por meio de equações aplicadas a modelos numéricos de representação altimétrica, os MDTs, que derivam os atributos.

De acordo com os trabalhos desenvolvidos no Laboratório de Geologia Ambiental da UFSM apoiado nos trabalhos de Moore et al. (1991; 1993), Wilson \&Gallant (2000), Chagas (2006), Silveira et al. (2012) e Silveira et al. (2013) os atributos derivados de MDT são compreendidos aqui como atributos topográficos. A parametrização da morfologia é designada, neste trabalho, por geomorfometria (geomorphometry), ou análise digital do relevo (SILVEIRA et al., 2013).

Os atributos topográficos podem ser parametrizados a partir de variáveis, tais como altitude, declividade, aspecto, diferentes curvaturas (em plano, perfil), área de contribuição, índice topográfico de umidade, entre outros (McBRATNEYet al., 2003).

O perfil de curvatura e plano de curvatura são importantes para o entendimento de processos (CHAGAS, 2006 e SIRTOLI et al., 2008). O primeiro refere-se ao caráter convexo/côncavo do terreno, quando analisado em perfil (VALERIANO, 2003) e o segundo refere-se ao caráter divergente/convergente dos fluxos de matéria sobre o terreno quando analisado em projeção horizontal (VALERIANO e CARVALHO JÚNIOR, 2003).

Para definir unidades de relevo básicas para o mapeamento geomorfológico e pedológico Dikau (1989); Moore et al. (1991) utilizaram os atributos de declividade, plano e perfil de curvatura. Silveira et al. (2012) e Silveira et al. (2013) usaram técnicas de geoprocessamento que possibilitam a representação paramétrica do relevo a partir de um Modelo Digital do Terreno, do qual são calculados atributos topográficos primários e secundários, com o objetivo de delimitar unidades preliminares de mapeamento de solos.

Definiu-se a unidade bacia hidrográfica como unidade de análises geomorfológicas por esta definir a esculturação do relevo. As bacias de drenagem são tratadas como unidades geográficas onde os recursos naturais se integram e além de constituírem-se em uma unidade de fácil reconhecimento, servem para o ordenamento territorial.

Para caracterizar a bacia hidrográfica busca-se uma análise quantitativa do 
relevo através de parâmetros morfométricos (altimetria, dimensões, desníveis, extensões)e da morfologia (formas do perfil, concavidades, convexidades, rupturas, topos e fundos de vale).

Desta forma, o presente estudo foi realizado na bacia hidrográfica do Arroio Caverá, localizada na região oeste do Rio Grande do Sul (RS), cuja área é de 1.459 km² (Figura 1), por meio de técnicas de geoprocessamento associadas à análise digital do relevo onde determinou-se a representação paramétrica das formas do relevo, com emprego de atributos topográficos obtidos de um Modelo Digital do Terreno, elaborando-se uma compartimentação geomorfométrica. 


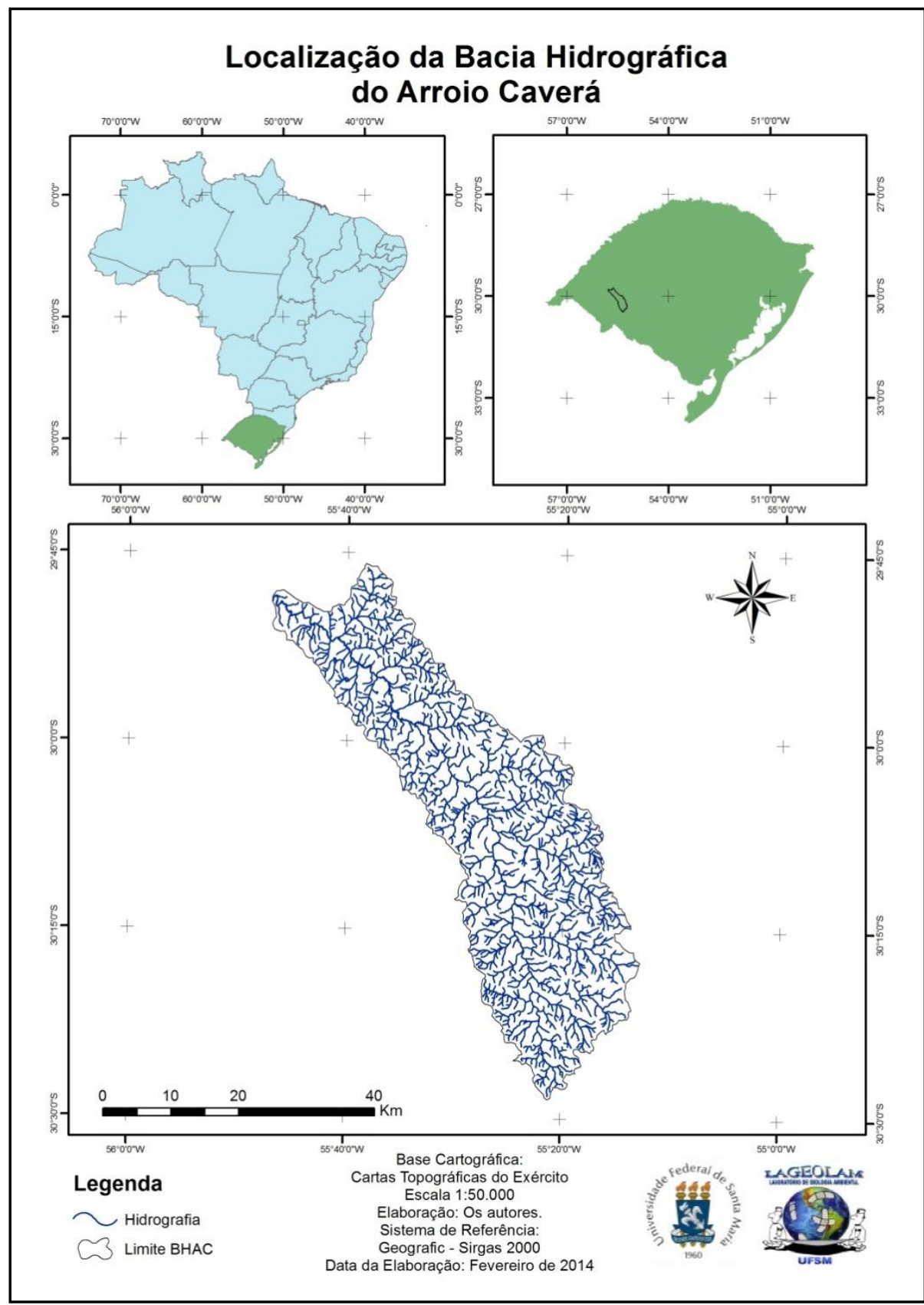

Figura 1: Mapa de localização da bacia hidrográfica do Arroio Caverá.

\section{MÉTODO}

Para realização da classificação do relevo da bacia hidrográfica do Arroio Caverá utilizou-se uma proposta de mapeamento geomorfométrico automatizado apresentado por Silveira \& Silveira (2013), a partir dos preceitos de Iwahashi e Pike (2007). Tal classificação é realizada através do cruzamento de informações e atributos 
topográficos gerados por meio de um SIG e hierarquizados através de uma árvore de decisão baseada em valores pré-definidos, com base em conhecimento da área. Foram empregados quatro atributos topográficos: altimetria, declividade, perfil de curvatura e plano de curvatura.

Como base cartográfica utilizada para a geração dos atributos topográficos, utilizou-se as cartas topográficas do exército em escala 1:50.000, sobre as quais foram extraídas as informações das curvas de nível de equidistância de 20 metros somadas aos pontos cotados presentes na área. Através dos mesmos, realizou-se a interpolação destas informações altimétricas utilizando-se o interpolador ANUDEM (Hutchinson 1989, 1996, 2008), disponível como ferramenta no aplicativo ArcMap versão 10.1 (ESRI, 2013), que cria um modelo digital do terreno hidrologicamente consistentes.

Ao se trabalhar com as informações altimétricas em uma bacia hidrográfica, possibilita-se analisar as condições mais propícias a processos de dissecação para as áreas de maior altitude e processos de acumulação ou deposição dos sedimentos relacionados às áreas de maior para as áreas de menor altitude. Permitem-se, ainda, análises das variações de amplitude apresentadas pela bacia hidrográfica. No referido trabalho estas informações foram consideradas em função da distribuição do histograma de frequência, onde foi considerada a média geral das altimetrias que corresponde a 150 metros. A escolha por este valor como limite corresponde ainda à sua proximidade com uma situação de quebra natural do relevo, ou seja, a base da serra do Caverá que nesta área apresenta as altitudes próximas a 180 metros.

A partir deste modelo digital de terreno, são geradas as demais informações pertinentes à compartimentação geomorfométrica. A primeira informação adquirida deste modelo são as informações de declividades que no presente trabalho foi gerado por meio do polinômio de Horn (1981). A declividade corresponde a um dos mais importantes parâmetros na análise das vertentes, pois representa sua inclinação. Estas informações foram discretizadas em duas classes cujo limite é de 5\%. As vertentes com altas declividades estão mais sujeitas a processos denudacionais, enquanto as de baixa são propícias aos processos agradacionais.

As vertentes podem ser definidas de forma simplificada como um elemento da superfície terrestre inclinado em relação à horizontal, que apresenta um gradiente e uma 
orientação no espaço (VELOSO, 2002), e dessa forma podem ser classificadas de acordo com a sua curvatura no plano ou em perfil.

O plano de curvatura da vertente são também informações derivadas do MDT e corresponde à variação do gradiente de arqueamento na direção ortogonal da vertente (curvatura da superfície perpendicular à direção da inclinação) e refere-se ao caráter divergente/convergente do terreno, enquanto, o perfil de curvatura é a taxa de variação do gradiente de arqueamento na direção de sua orientação (a curvatura da superfície no sentido do declive) e está relacionada ao caráter convexo/côncavo do terreno sendo decisiva na aceleração ou desaceleração do fluxo da água sobre o mesmo. Ambos foram obtidos a partir do MDT por meio do emprego do polinômio de Zevenbergen e Thorne (1987).

O perfil das vertentes, em ambiente SIG, é analisado de acordo com seu valor de curvatura (histograma de frequência) e teoricamente, vertentes retilíneas têm valor de curvatura nulo, vertentes côncavas os têm positivos e convexas têm curvatura negativa (VALERIANO, 2003). Porém, vertentes com valores nulos são muito raras na natureza, assim muito pouco do que se julga retilíneo apresenta valor de curvatura realmente nulo, mas sim valores pertencentes a um intervalo de tolerância na vizinhança desse valor.

A classificação do plano das vertentes, em ambiente SIG, é analisada de acordo com o seu histograma de frequência que indica o valor da referida curvatura. Semelhante ao perfil, os valores nulos correspondem à inexistência de curvatura em vertentes planas,já os valores positivos representam curvatura divergente e os valores negativos correspondem à curvatura convergente.

Para a compartimentação geomorfométrica do referido trabalho, optou-se pela classificação das curvaturas das vertentes em duas classes: quanto ao perfil em côncavas e convexas e quanto ao plano em convergentes e divergentes, conforme tabela1.

Tabela 1: Classificação das informações básicas para a determinação das unidades geomorfométricas.

\begin{tabular}{|c|c|c|c|}
\hline Altitude & Declividade & Plano & Perfil \\
\hline $1-<$ Média & $1-<5 \%$ & 1 - Convergente & 1 - Convexo \\
\hline $2->$ Média & $2->5 \%$ & 2 - Divergente & 2 - Côncavo \\
\hline
\end{tabular}


Através do cruzamento das informações utilizando-se a árvore de decisão apresentada no fluxograma da figura 2 , foram identificadas 12 unidadesgeomorfométricas que representam a distribuição espacial das características.

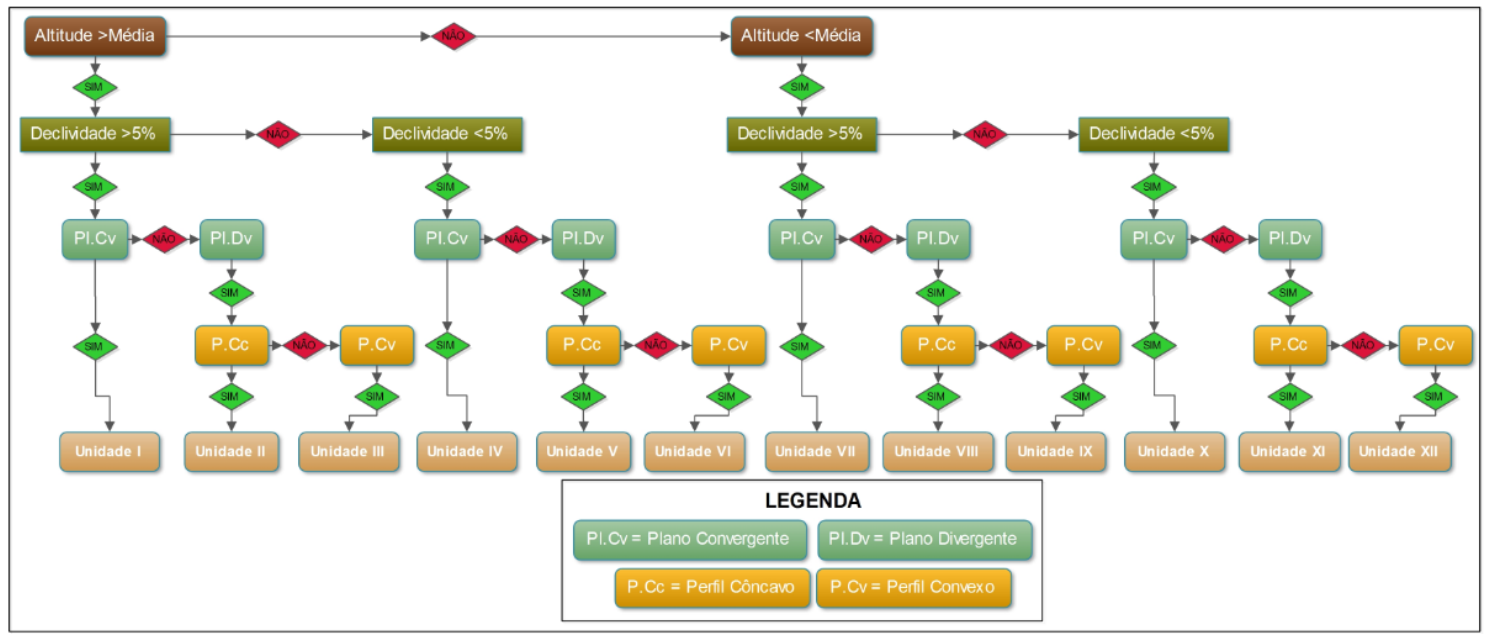

Figura 2: Fluxograma apresentando a árvore de decisão utilizada para a definição das unidades geomorfométricas.

\section{RESULTADOS}

Neste trabalho foram utilizados os atributos altitude, declividade, perfil e plano de curvatura para definir as unidades de relevo.A área de estudo apresenta como menor cota altimétrica o nível de 77 metros, junto à planície do Arroio Caverá onde o arroio deságua no Rio Ibirapuitãe a maior cota é de 366 metros, resultando em uma amplitude altimétrica de $289 \mathrm{~m}$.

O atributo de declividade é um dos mais utilizados para caracterização do relevo, pois permite uma primeira indicação dos processos morfogenéticos atuantes. As declividades acima de 5\% marcam o limite de ocorrência predominante de processos morfogenéticos erosivos. Essa informação permite a primeira divisão entre o predomínio de processos pedogenéticos de acumulação e os processos morfogenéticos.

Hugget (1975) estabelece a combinação de formas de vertentes associando a curvatura vista em perfil e em plano; propõe nove padrões ideais para indicações das direções dos fluxos da água sobre as vertentes, cujas diferenças nos solos e na paisagem são resultantes, em parte, do movimento da água e sua distribuição nas vertentes. 
A curvatura no perfil é a taxa de variação da declividade na direção do aspecto enquanto a curvatura no plano é a taxa de variação da declividade na direção ortogonal a do aspecto (MENDIONDO et. al, 1998).

O perfil de curvatura é importante para caracterizar mudanças na velocidade do fluxo da água e processos relacionados ao transporte de sedimentos, enquanto que o plano de curvatura demonstra a propensão da água a convergir ou divergir no terreno (GALLANT e WILSON, 2000).

Assim, o perfil de curvatura representa a forma da vertente no sentido descendente e indica a proporção de mudança do potencial do gradiente, influenciando no fluxo da água e na velocidade de processos de transporte de sedimentos.

O plano de curvatura representa a medida da convergência e divergência topográfica e por isso influencia a concentração de água na paisagem (SIRTOLI et al., 2008).

Baseando-se nos parâmetros descritos foram classificados os tipos de vertentes e se estabelece o zoneamento das unidades de relevo. Para a Bacia Hidrográfica do Arroio Caverá foram definidas 12 unidades de relevo, que serão descritas a seguir e apresentadas na tabela 2. A figura 3 apresenta os mapas com as Unidades geomorfométricas I a VI da bacia hidrográfica do Arroio Caverá.

Tabela 2: Áreas e respectivas porcentagens das unidades geomorfométricas da bacia hidrográfica do Arroio Caverá.

\begin{tabular}{|l|r|r|}
\hline \multicolumn{1}{|c|}{ Unidade } & \multicolumn{1}{|c|}{ Área_km $\mathbf{k m}^{\mathbf{2}}$} & \multicolumn{2}{c|}{ Porcentagem } \\
\hline Unidade I & 138 & 7,5 \\
\hline Unidade II & 104,7 & 7,9 \\
\hline Unidade III & 114,9 & 7,1 \\
\hline Unidade IV & 103 & 3,8 \\
\hline Unidade V & 55,6 & 5 \\
\hline Unidade VI & 73 & 6,3 \\
\hline Unidade VII & 91,7 & 5,9 \\
\hline Unidade VIII & 85,9 & 2,7 \\
\hline Unidade IX & 39,4 & 21,6 \\
\hline Unidade X & 315,1 & 14,1 \\
\hline Unidade XI & 205,4 & 9,1 \\
\hline Unidade XII & 132,5 & \\
\hline
\end{tabular}


A unidade I cobre $138 \mathrm{~km}^{2}$, representando9,5\% do total da área da bacia, sendo mais expressiva no alto curso da bacia, ocorrendo também, com menor intensidade no médio curso e com pouca expressão no baixo curso, restrita aos limites da bacia. Predominam processos morfogenéticos de erosão devido à declividade superior a 5\%, localização predominantemente nos topos das vertentes e maior concentração da água devido ao plano de curvatura ser convergente.

A unidade II cobre uma área de $104,7 \mathrm{~km}^{2}$, próximo a $7,2 \%$ da área da bacia, assim como a unidade I ocorre predominantemente no alto curso da bacia, com menor intensidade no médio curso e com pouca expressão no baixo curso, restrita aos limites da bacia. Ocupa principalmente o terço superior das vertentes em altitudes maiores que a média, apesar da declividade ser maior que $5 \%$ os processos erosivos podem ser atenuados devido ao perfil côncavo e plano de curvatura divergente, o que faz com que a água seja dissipada com menor velocidade.

A unidade III, cobre aproximadamente $114,9 \mathrm{~km}^{2}$, sendo $7,9 \%$ do total da área da bacia,ocorrendo predominantemente nas porções do alto curso da bacia estendendo-se até o médio e baixo curso pelos divisores d'água. Ocorre predominantemente no topo das vertentes por vezes estendendo-se a meia vertente, principalmente no alto curso da bacia. Caracteriza-se pela altitude maior que a média e declividade maior que 5\%, o que pode levar à ocorrência de processos erosivos acentuados devido ao aumento da velocidade do fluxo (perfil convexo) e dissipação da água (plano divergente).

A unidade IV, cobre aproximadamente $103 \mathrm{~km}^{2}$, correspondendo a $7,1 \%$ da área da bacia hidrográfica, distribui-se principalmente pelo alto e médio curso da bacia, no baixo curso, com pouca expressão, restringe-se aos limites da bacia, sendo o limite leste de maior expressão. Ocorre no topo das vertentes, estendendo-se até a meia vertente, caracteriza-se pela declividade inferior a $5 \%$ e plano de curvatura convergente. 


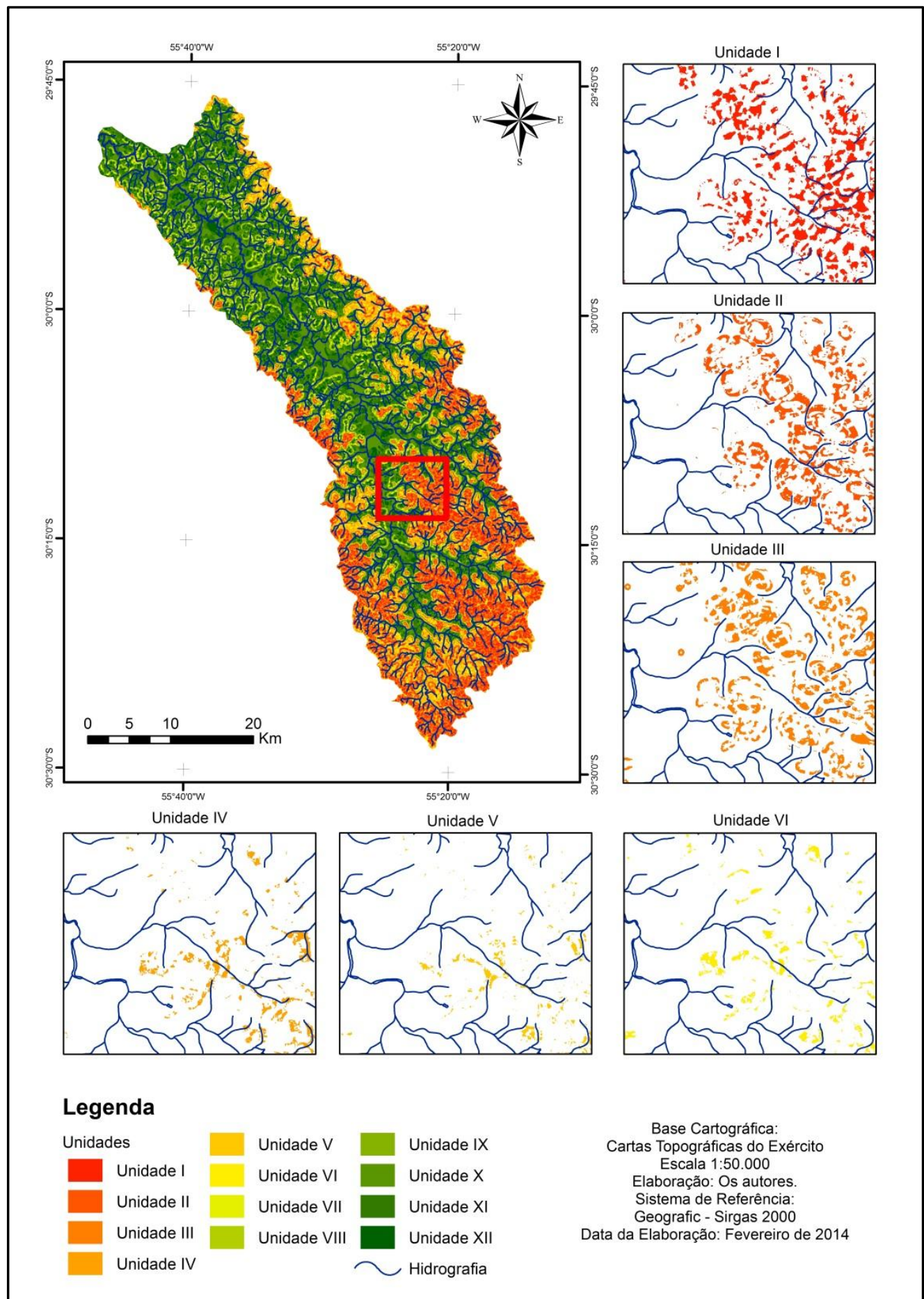

Figura 3:Mapas das unidades geomorfométricas I a VI da bacia hidrográfica do Arroio Caverá.

A unidade $\mathrm{V}$ cobre aproximadamente $55,6 \mathrm{~km}^{2}$, correspondendo a aproximadamente $3,8 \%$ da área da bacia,ocorre principalmente pelo alto e médio curso da bacia, no baixo curso, com pouca expressão, restringe-se aos limites da bacia, sendo o limite leste de maior expressão.Distribui-se predominantemente pelo terço superior e 
médio das vertentes. Apesar da declividade inferior a 5\% e perfil côncavo, provavelmente não ocorram significativos processos de acumulação devido ao plano de curvatura divergente.

A unidade VI, cobre aproximadamente $73 \mathrm{~km}^{2}$, correspondendo a 5\% da área da bacia,ocorre principalmente pelo alto e médio curso da bacia, no baixo curso, com pouca expressão, restringe-se aos limites da bacia, sendo o limite leste de maior expressão, ocorrendo nos terços superior e médio da vertente. Pelas características do perfil e plano de curvatura da unidade (convexo e divergente), pode-se considerar que há aumento da energia do fluxo, porém, pela declividade inferior a 5\%, os possíveis processos erosivos são atenuados.

A unidade VII cobre $91,7 \mathrm{~km}^{2}$, representando em torno de $6,3 \%$ do total da área da bacia. Ocorre predominantemente no médio e baixo curso da bacia, ocupando principalmente a região da meia vertente, ocorrendo também, com menor expressão, no alto curso, por vezes próxima às drenagens.Caracteriza-se pelo plano de curvatura convergente e declividade superior a 5\%, o que pode formar canais de concentração de água e possibilidade de processos morfogenéticos de erosão.

A figura 4 apresenta os mapas com as unidades geomorfométricas VII a XII da bacia hidrográfica do Arroio Caverá.

A unidade VIII cobre uma área de $85,9 \mathrm{~km}^{2}$, próximo a 5,9\% da área da bacia. Ocorre predominantemente no médio e baixo curso da bacia ocorrendo também, com menor expressão, no alto curso,por vezes próxima às drenagens. Assim como a unidade VII, predomina no terço médio das vertentes localizadas no baixo e médio curso, por vezes próximo à drenagem. Caracteriza-se pela diminuição da energia e dissipação do fluxo na vertente (perfil côncavo e plano divergente), bem como pela possibilidade de ocorrência de processos erosivos devido à declividade superior a 5\%.

A unidade IXcobreaproximadamente $39,4 \mathrm{~km}^{2}$, sendo $2,7 \%$ do total da área da bacia. Ocorre predominantemente no médio e baixo curso da bacia ocorrendo também, com pouca expressão, no alto curso, por vezes próxima às drenagens, sobretudo no terço médio da vertente. Há o predomínio de processos morfogenéticos de erosão pela declividade superior a 5\% associada ao aumento da energia e dissipação do fluxo (perfil convexo e plano divergente). 


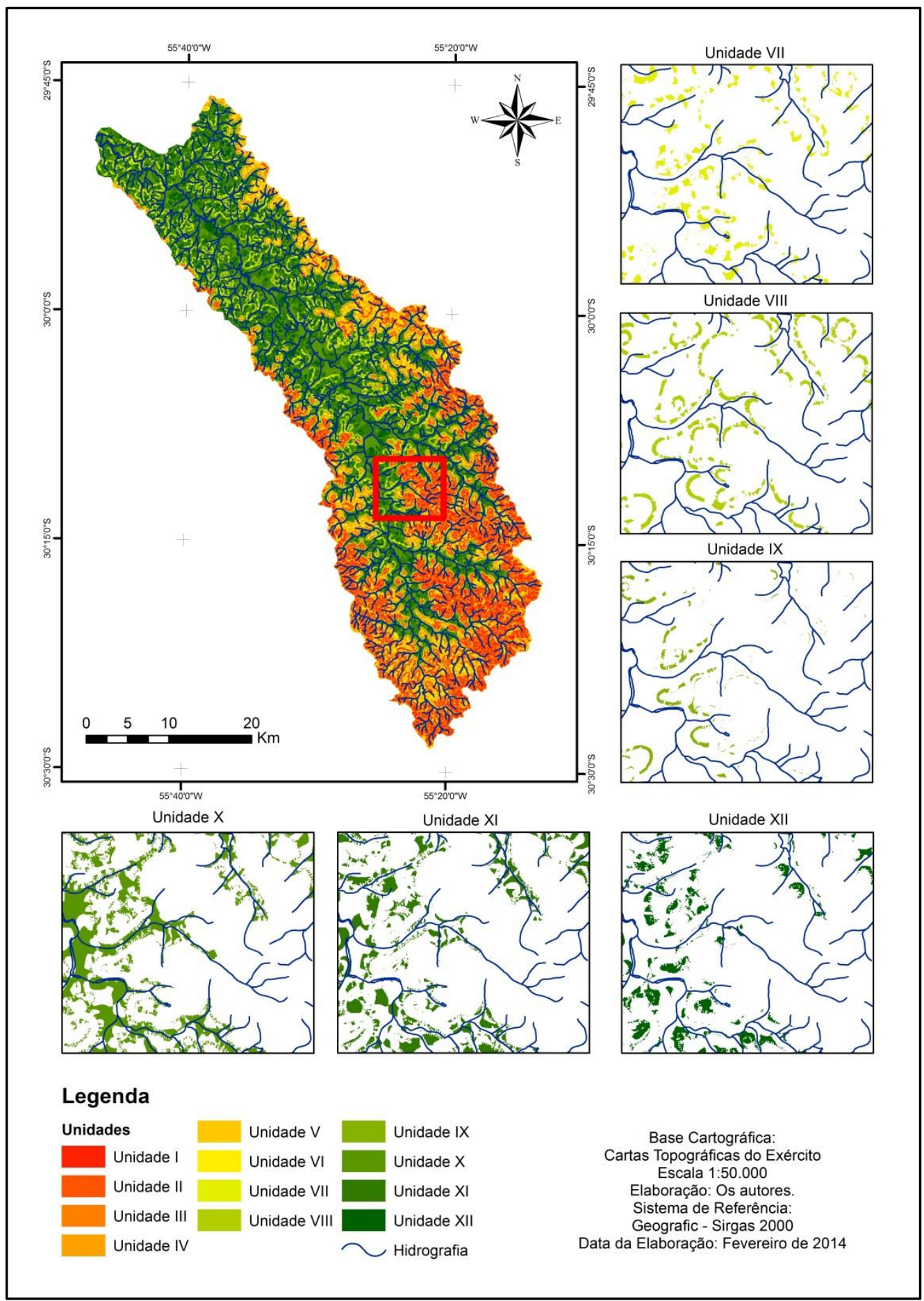

Figura 4:Mapas das unidades geomorfométricas VII a XII da bacia hidrográfica do Arroio Caverá.

A unidade $\mathrm{X}$ cobre aproximadamente $315,1 \mathrm{~km}^{2}$, correspondendo a $21,6 \%$ da área da bacia. Ocorre com predominância quase absoluta no baixo curso, com grande expressão no médio curso e no alto curso sua área de ocorrência é significativamente menor. Estende-se por todas as porções das vertentes do médio e baixo curso 
(declividade inferior à média), inclusive junto ao curso principal do Arroio, formada por áreas de declividades inferiores a 5\%, caracteriza-se pela concentração do fluxo convergindo na base da vertente (plano convergente).

A unidade XI cobre aproximadamente $205,4 \mathrm{~km}^{2}$, correspondendo a aproximadamente $14,1 \%$ da área da bacia. Ocorre com predominância quase absoluta no baixo curso, com grande expressão no médio curso e no alto curso sua área de ocorrência é significativamente menor. Encontra-se principalmente no terço médio e inferior das vertentes, em altitudes inferiores à média e declividade menor que $5 \%$. Caracterizada pela diminuição da energia do fluxo divergente (perfil côncavo e plano divergente).

A unidade XII cobre aproximadamente $132,5 \mathrm{~km}^{2}$, correspondendo a $9,1 \%$ da área da bacia. Ocorre predominantemente no baixo curso, estendendo-se até o médio curso e de forma menos expressiva no alto curso. Predomina nos terços superior e médio das vertentes no médio e baixo curso (altitude inferior à média) e por vezes no terço inferior junto à planície de inundação. Caracteriza-se pelo aumento da velocidade do fluxo em direção à base da vertente (perfil convexo), porém com fluxo divergente (plano divergente).

\section{CONSIDERAÇÕES FINAIS}

A compartimentação geomorfométrica utilizando-se da classificação digital das unidades através da árvore de decisão com base nas características físicas do meio relacionadas à altitude, declividade, plano e perfil de curvatura das vertentes permite a divisão da bacia hidrográfica em áreas com características geomorfometricamente semelhantes quanto aos processos erosivos e de sedimentação.

Foram definidas para a bacia hidrográfica do Arroio Caverá 12 unidades. Dentre as unidades definidas destacam-se as unidades X e XI que apresentam as maiores áreas espacialmente distribuídas pela bacia hidrográfica, ocupando juntas aproximadamente $36 \%$ da área total e caracterizam-se pelas altitudes inferiores à média e declividades inferiores a $5 \%$ associadas quase que exclusivamente ao baixo curso da bacia, o que demonstra grandes áreas planas relacionadas aos processos deposicionais. 
O desenvolvimento de trabalhos de compartimentação geomorfométrica além de enriquecerem o conhecimento sobre a região oeste do Rio Grande do Sul com a disposição de produto cartográfico obtido, permite considerar que a metodologia utilizada é adequada para caracterização das vertentes da área de estudo e a espacialização dos processos presentes, demonstrando grande potencial para suporte em trabalhos que relacionem as características do relevo com outros atributos ambientais e de uso do solo.

\section{REFERÊNCIAS BIBLIOGRÁFICAS}

CHAGAS, C. S. Mapeamento digital de solos por correlação ambiental e redes neurais em uma bacia hidrográfica no domínio de mar de morros. Viçosa, 2006.223p. (Doutorado -Universidade Federal de Viçosa- UFV).

DIKAU, R. The application of a digital relief model to landform analysis in geomorphology. In: RAPER, J. (Ed.). Three-dimensional applications in geographic information systems.New York: Taylor and Francis, p.51-77, 1989.

GALLANT, J. C.; WILSON, J. P. Primary topographic attributes. In: WILSON, J. P.; GALLANT, J. C. (Eds.). Terrain Analysis: Principles and applications. New York: John Wiley, p.51-85, 2000.

HORN, B. K. P. Hill shading and the reflectance map. Proceedings of the IEEE, n. 69, v. 01, p. 14-47, 1981.

HUGGET, R. J. Soil Landscape Systems: A model of soil genesis. Geoderma, v.13, p.01-22, 1975.

HUTCHINSON, M. F. A new procedure for gridding elevation and stream line data with automatic removal of spurious pits.Journal of Hydrology, 106, 211-232, 1989.

A locally adaptive approach to the interpolation of digital elevation models. In: International Conference/Workshop on Integrating GIS and Environmental Modeling, National Center for Geographic Information and Analysis. 3. 1996, Santa Bárbara. Proceedings... Santa Bárbara: University of California, 1996. CD-RON. 
Adding the $\mathrm{Z}$ dimension. In: WILSON, J. P.; FOTHERINGHAM, A.S. The handbook of geographic information science.1.ed.Blackwell Publishing Ltd. 2008. p. 144-168.

IWAHASHI, J.; PIKE, R. J. Automated classifications of topography from DEMs by an unsupervised nested-means algorithm and a three-part geometric signature.Geomorphology 86(3-4): 409-440, 2007.

McBRATNEY, A. B.; MENDONÇA-SANTOS, M. L.; MINASNY, B.On digital soilmapping.Geoderma, v. 117, p. 3-52, 2003.

MENDIONDO, E. M.; COLLISCHONN, W.; BULHÕES MENDES, C. A. Modelos numéricos do terreno e suas aplicações a bacias hidrográficas 2: Obtenção de atributos. In: XVII Congreso Nacional del Agua / II Simposio de Recursos Hídricos del Cono Sur. Anais...1998.

MOORE, I. D.; GESSLER, G.A.; PETERSON, G.A.Soil attribute prediction using terrain analysis.Soil Science Society of America Journal, v.57, p.443-452, 1993.

MOORE, I.D., GRAYSON, R.B., LADSON, A. R. Digital terrain modeling: A review of Hydrological, geomorphological an biological applications. Hydrological Processes, v. 5, p. 3-30, 1991.

SILVEIRA, C.T.; SILVEIRA, R.M.P. Classificação geomorfométrica de unidades morfológicas do relevo no estado do Paraná obtida de atributos topográficos e árvore de decisão. Anais do XV Simpósio Brasileiro de Geografia Física Aplicada. Vitória/ES. 2013.

SILVEIRA, C. T. OKA-FIORI, C.; SANTOS, L. J. C; SIRTOLI, A. E.; SILVA. Pedometria apoiada em atributos topográficos com operações de tabulação cruzada por álgebra de mapas. Revista Brasileira de Geomorfologia, v.13, n.2, p.125$137,2012$.

SILVEIRA, C. T. OKA-FIORI, C.; SANTOS, L. J. C; SIRTOLI, A. E.; SILVA, C. R.; BOTELHO, M. F. Soilpredictionusing artificial neural networks andtopographicattributes. Revista Geoderma 195-196, p. 165-172, 2013.

SIRTOLI, A. E.; SILVEIRA, C. T.; MONTOVANI, L. E.; SIRTOLI, A. R. A.; OKAFIORI, C. Atributos do relevo derivados de modelo digital de elevação e suas relações com solos. Scientia agraria, v.9, n.3, p.317-329, 2008. 
TRENTIN, R. Mapeamento geomorfológico e caracterização geoambiental da bacia hidrográfica do rio Itu - oeste do Rio Grande do Sul - Brasil. 2011. 215 f. Tese de Doutorado - PPGGeografia/UFPR, Curitiba. 2011.

VALERIANO, M. M. Curvatura vertical de vertentes em microbacias pela análise de modelos digitais de elevação. Revista Brasileira de Engenharia Agrícola e Ambiental, Campina Grande, v.7, n.3, p.539-546, 2003.

VALERIANO, M. M.; CARVALHO JÚNIOR, O, A. Geoprocessamento de modelos digitais de elevação para mapeamento da curvatura horizontal em microbacias. Revista Brasileira de Geomorfologia, v 4, n.1, p.17-29, 2003.

VELOSO, A. A importância do estudo das vertentes. Geographia, v. 4, n. 8, p 1-5, 2002.

WILSON, J. P.; GALLANT, J. C. Digital terrain analysis, chapter 1. In: WILSON, J. P.; GALLANT, J. C. (Eds.). Terrain analysis: principles and applications. New York: John Wiley \& Sons, p.1-27, 2000.

WOOD, J. The geomorphological characterisation of digital elevation models.Leicester, UK, 1996. 185p. PhD Thesis - University of Leicester.Disponível em: http://www.soi.city.ac.uk/ jwo/phd.

ZEVENBERGEN, L.W.; THORNE, C.R. Quantitative Analysis of Land Surface Topography.Earth Surface Processes and Landforms, v.12, p.47-56, 1987.

Artigo recebido para publicação em dez/13

Artigo aceito para publicação em março/14 